\title{
E -Recruitment Transforming the Dimensions of Online Job Seeking: A Case of Pakistan
}

\author{
Shuaib Ahmed \\ Assistant Professor \\ Hammad Tahir \\ Assistant Professor \\ Syed Waleed Ali Warsi \\ Assistant Manager Operations \\ Institute of Business \& Technology, Karachi \\ Doi:10.5296/ijhrs.v5i1.6161 \\ URL: http://dx.doi.org/10.5296/ijhrs.v5i1.6161

\begin{abstract}
This research study aims to investigate the influence of adoption of e-recruitment method by job seekers in Karachi, Pakistan. It also analyzes the relationship between e-recruitment and their adoption behavior. A convenient sample of 250 job seekers from different universities students of Karachi was taken. After validating the instrument, one sample t-test was performed to test the relationship of selected variables i.e. cost saving, time saving, extensive search and unlimited excess with the behavior of job seekers in adopting a e-recruitment method. Using SPSS 17.0 Statistical evidence at 0.05 level of significance proved that cost saving, time saving, extensive search and unlimited excess are significantly correlated with a e-recruitment adoption. The findings are helpful for academicians, organizations and other institutions to design and market new web pages to attract more and more job seekers.
\end{abstract}

Keywords- Recruitment, Online, Job Market, Pakistan

\subsubsection{Introduction}

The traditional method of recruitment has been revolutionized by the emergence of the Internet. In the past few years, the Internet has dramatically changed the face of HR recruitment and the ways organizations think about the recruiting function in Pakistan, especially in private sector. Using the power of Internet to achieve HR goals not only increases productivity but also saves time and money. E-recruitment is the processes of recruiting personnel by using internet or other electronic sources. By using E Recruitment services job seekers get a better chance to increase their prospective job opportunities. These services gives time flexibility and more chances to attract passive job seekers as well resulting in better chance to get best match for hiring needs. In the coming years, digital 
recruiting and hiring are expected to continue their explosive growth. Presently, erecruitment has been adopted in many organizations in Pakistan from large organizations to small size companies. Most organizations are already using e- recruitment to post jobs and accept resumes on the Internet and correspond with the applicants by e-mail. In today's dynamic era internet has revolutionized the world and turned it into a global village, job searching around the world has become very common for those candidates who are expert in browsing and have access to internet. Now a days job searching on internet has became a very common tool for job seekers. It allows them to find their desired job and build their career in any part of the world.

The online recruitment trend was started in the western countries since last decade of the $20^{\text {th }}$ century. In Pakistan, this trend has grown since last seven years. Thousands of CVs are sent or uploaded daily on company's websites and online agencies. The internet seems the perfect venue for jobseekers \& head hunters. The efficient searches of the appropriate Job or a Candidate increase the hits on this unique system. Now there are two contemporary approaches for job searching. First, traditional searching in which job seekers search the jobs through print media (newspapers, magazines) they also have used other channels to get a job such as, recruiters, employee referrals, walk-in interviews and employment agencies (Breaugh,1992). Second, Internet searching, thousands of job seekers using internet effectively to get information to prospective employer, many of them are seeking company website, contact online recruiters available on different job portals, register themselves on online job boards or online job agencies. Those sites ultimately act as medium that connect the job seekers with companies.

There are many advantages of using web based job searching; it enhances the efficiency of job seekers, it saves candidate's process cost and time, job seekers can reach employer at worldwide level, in contrast to any traditional searching method, which would reach a local or national group (CIPD, 1999). Since 2005, job seekers in Karachi city focusing extensively on online sources to avail opportunities. The massive job search on internet shows a positive growth in internet users. Internet access in universities and offices also facilitates people to search and apply online. Most of the students and professionals are regularly visiting the corporate website for possible job opening and submitting their documents for future opportunities.

\subsection{Internet in Pakistan}

Internet access has been available in Pakistan since the early 1990s. PTCL started offering access via the nationwide local call network in 1995. Use of internet in Pakistan increases day by day it became an integral part of the nation, especially young generation. However, the large portion of populace, using internet, belongs to urban areas. Karachi, Islamabad and Lahore are the major cities using the massive chunk of internet service, moreover, service providers generating the large amount of their revenue from these cities. 
Pakistan's growth rate of internet users is second highest in SAARC countries in accordance with its population, as it standing at 16.8 percent as compared with 28.3 percent of Maldives. According to the State Bank of Pakistan (SBP) publications quoted World Bank statistics by July 2012, Pakistan internet users showed double digit growth from past five years. The growth rate stood at 10 percent in 2007, which is now more than 16 percent. The internet users growth rate in India is standing at 7.5 percent; 12.1 percent in Sri Lanka, 13.6 percent in Bhutan with respect to their populations, World Bank statistics said.

In Pakistan, the internet users' growth rate is on the rise through the services of broadband internet and mobile phone services. According to Internet Service Providers Association of Pakistan (ISPAK), the estimated internet users have reached 25 million in the country thanks to broadband and mobile phone operators. The internet users having demand of high speed services are also increasing particularly through broadband operators exploiting various technologies such as Wimax, EvDO, FTTH. As per industry estimate, there are more than five million broadband users in the country through connections of 2 million. The internet users mainly do connect with one IP or connections and consume internet services through sharing at home, office and educational institutions.

There are 50 internet services providers in which 10 are broadband companies exploring untapped market in big cities, making it available for people to use internet with only Rs 100. Among 25 million internet users, more than 15 million of them avail internet services trough mobile phones thanks to cellular operators' packages and awareness drive.

The mobile phone subscribers go online through different internet services including, EDGE, GPRS and Blackberry Internet Services (BIS). Majority of the mobile phone subscribers use internet services for browsing, emails, Facebook and Twitter as cellular phone operators introduced different affordable packages to their subscribers. Moreover low cost handsets also facilitate a large number of people to connect online 24 hours. The cellular phone companies have been working aggressively on the promotion of Internet services for last two years mainly for earning extra revenues besides voice calls and text messages. These companies introduced different bundle packages of Internet services in their youth brands to promote Internet services as an essential for young customers for education and entertainment purposes.

The rising internet utility among the masses have increased the searching for jobs not only for careers but also living standard of the people, communications and information purpose, commercial means such as credit and money transactions by branchless and mobile banking. The growth in internet users pave the way towards growth in different sector particularly the access of information and entertainment at affordable purpose but it should be controlled by the watchdog, Pakistan Telecommunication Authority (PTA).

\subsection{Literature Review}

In the modern era the ways of recruitment has refined drastically and the emergence of erecruitment has changed the business landscape forever on an international level and as well in context to country. Due to constant surge towards innovation in information technology and grasping ways to provide more efficient ways for 
businesses to grow substantially, the inception of e-recruitment seem to be the most viable thing for many firms operating in vibrant environment. The swift changes in technology have changed the system of the society and this change leads towards the smart, well organized social structure. The impact of technology on business is further reflected by the continuous rise in amount of literature exploring the effects of new technology development and implementation on the efficiency of business, including the impacts on human resource practices (Dessler, 2002). Bush et al (2002) demonstrated that the adaptation of the web as a medium by organizations has been faster than any other medium in history. Organizations periodically recruit in order to add, to maintain, or readjust their work forces in accordance with HR requirements (Cascio, 1998). Recruitment is an important part of human resource process. It is a two way process which involved employers (Organizations) and applicants (Job seekers). Cascio (1998) identified organization searching for prospective employees as a prospecting theory of recruitment. In practice, however, prospective employees seek out organizations as well. This view, termed as a mating theory of recruitment, appears more realistic. The assessment of attraction from both parties continues from the initial recruitment process through to the final appointment outcome (Breaugh, 1992). The traditional recruitment process are readily acknowledge as being time consuming with long hiring cycle times, high cost per process and minimal geographic reach (Lee, 2005). On the other hand, indeed, the internet has changed the recruitment, the first and important stage of human resource management process, from an organizational and a job seekers point of view (Warner, 2005).

There are numerous articles which review the perceived advantages and disadvantages of Internet job searching as a source when compare to the more traditional sources including newspapers, employment agencies, referrals and walk-in.

In developed countries, among jobseekers, it is reported that an estimated one in four utilize the internet to source job opportunities (Smith et al., 2004), moreover, 75\% of HR professionals utilize internet recruitment methods i.e. online job boards. Unfortunately, the data of Pakistani jobseekers, who applied online, is not available. The increasing use of the Internet as a job searching tool has arise via a number of means as identified by the Chartered Institute of Personnel and Development (CIPD, 1999). The three most common means of job searching via the web are:

- The Career page of the organization's website.

- The specialized recruitment websites, which act as a medium between organizations and potential applicants, such as online job boards, job portals, job agencies and online recruiters.

- The media sites which involves placing an advertisement in a more traditional media such a s a newspaper which also has its own website and post the same advertisement simultaneously on the website, usually for free.

Online job searching and recruiting also extends to more interactive recruitment tools, creating an avenue to build relationships between job seekers and organizations (Mooney, 2002). E-job searching and e-recruitment tools are acknowledged as being an important aspect of internet job searching and recruiting for jobseekers and organizations, their impact occurs after the initial recruitment stage and during the selection stage.

It has been found through many empirical studies that e-recruitment shall not completely 
overpower the traditional way of recruitment but shall help in finding the most appropriate candidate required for the given job.

Some of the scholars have researched that in order to develop a connection between employee satisfaction and size of firm, the type of e-recruitment policies, the use and integration of erecruitment play a critical role in overall process of e-recruitment. In order to gauge the effectiveness of the variables individual factors such as demographics, level of job satisfaction, job commitment and organizational commitment are the things which create a distinction between traditional recruitment methods and e-recruitment. E-recruitment enhances job seekers convenience in extraction of right type of information in a short time and applying organizations website quickly.

Through empirical studies, it has been concluded that the cost saving is one of dominant positives of e-recruitment as average print ads cost more than job ads on the internet web portals. The process of e-recruitment mainly such as the ease of placing ads on internet, filling application forms of various firms and also attaching resume to mails. E-recruitment also helps in attracting a diverse range of job seekers and also enhances the firm reputation in getting better applicants. Due to large amount of applications result in better screening of job applicants.

For job-seekers the access towards various company websites, recruitment firms and recruitment portals has opened unlimited avenue and result in searching for more and better opportunities to work and earn a better living. Galanaki (2002) conducted a comprehensive review of the literature on the use of the Internet by employers. Lower cost, shorter recruitment cycle; reach to a wider range of applicants, better quality of applicants, opportunity to address specific market niches, and attraction. The results addressed those applicants which entailed more information and very appealing to the customer in terms of pace and design. The world renowned companies use the portals effectively by depicting thorough information and also demanding more detail information of the applicants which result in reaching for a best candidate. The e-recruitment also results in finding better results since quick information in terms of feedback and follow-up by candidates who apply for a particular job.

Haddas (2004) develops a framework in which Internet recruitment lowered the cost in terms of screening better applicants. The researcher described that such e-recruitment decreases the proportion of well competent candidates. He found that applicant hired through internet stay for short period than those hired through employee referral system. The use of internet which provides accessibility to various people results in getting adequate feedback has become most vital source of extracting appropriate candidates for a specified job. However it does seem to undo a lot of positives such as generating many incompetent and undesirable candidates due to easy access. The use of internet has completely revolutionized the way organizations recruit these days and in terms of job seekers perspective. The previous traditional hiring methods produced high costs and high recruitment processes and cycles. The global coverage internet provides gets true recognition in terms of recruiter's through written communication by email, blogs and job portals. This era is particularly thriving by daily bases innovation as to how companies shall outwit and be ahead of their in terms of producing and making new products. The innovation has been on high side in terms of 
recruitment industry since many issues have been discussed at various forums. On s uch forums the recruiters basically discuss their e- recruitment experiences in order to further utilize various ongoing digital developments and incorporate in their fields. Employer Branding was one such issue and method that puts emphasis on organization as its main focus in terms of recruitment and where employers seek to find the most competent prospective employees for the given organization.

Social media is becoming a very potent tool since the numbers of the users are on the rise substantially. Through such social website it has become easier for recruiters as they search for candidate with utmost frequency and go through extensive research. Candidates can also be found and approached more quickly through Twitter or Facebook. The Recruitment industry looks for further improvements and improvises in making methods of e- recruitment more relevant in respect to costs and time consumption. The time is now to innovate and change and be got getter in terms of trying new things. Putting use of new mediums such as social networking sites can result in producing more suitable candidate experience. This way the recruiters can stay one step ahead of their rivals and therefore gaining benefits through effective utilization.

In a comprehensive review done by researchers such as Lang et al (2001) some key determinants were recognized by companies to use e-recruitment and implement on it thoroughly. From such findings such key indicators were (1) cost saving (2) less time consumption (3) greater volume of candidates, (4) greater accessibility in terms of time and place (5) recruiting qualified candidates at ease (6) increased employer branding (7) effective personnel selection (8) Providing organizational information (9) greater usage (10) targeted recruitment (11) constant update of job and applicant data (12) low cost in hiring suitable candidates (14) corporate policy. E-recruitment is on the rise with the existing trend of ongoing digital developments which has result in digital newspaper these days but all the factors cannot be realized as it was supposed to be like target orientation which offsets by poor segmentation, or reduction in time or cost for recruiting which could be offsets somehow due to high number of applicants that need to be evaluated.

\subsection{Hypotheses}

In the light of the literature review and research objective of this study, the following hypotheses were developed:

$\mathrm{H} 1$ : Cost saving is the predictor for online job seekers

$\mathrm{H} 2$ : Time saving the predictor for online job seekers

$\mathrm{H} 3$ : Extensive search is the predictor for online job seekers

H4: Unlimited access is the predictor for online job seekers

\subsection{Research Methodology}

An instrument was developed to test the content and validity for this research. A survey was 
conducted to investigate the key influencing factors towards E-recruitment adoption among job seekers in Pakistan. It further analyzes the relationship between E-recruitment and their adoption. To achieve the objective of this study a sample of 250 respondents was selected. The sample comprised of students from government and private sector universities in Karachi. Out of 250 respondents 134 were male(s) and 116 were female(s) which shows $53.6 \%$ and $46.4 \%$ respectively. Completed questionnaires were collected from the respondents' and data was entered in computer software. Finally the SPSS 17.0 was used for the estimation and analysis of the results.

\subsection{Findings \& Interpretation of Results}

The four hypotheses were constructed in the light of the literature review. To test each hypothesis one simple $t$ test technique was applied. Table 1 i.e. the descriptive table displays the sample size, mean, standard deviation, and standard error for each of the five variables. The sample means disperse around the 4 standard (agreed level). Table shows that there is no significant difference in all independent variable means i.e. Cost saving, time saving, extensive search, unlimited excess Thus, the mean of extensive search and unlimited excess are slightly higher than the rest of three variables.

Table 1: One-Sample Statistics

\begin{tabular}{|l|r|r|r|r|}
\hline & $\mathrm{N}$ & Mean & $\begin{array}{c}\text { Std. } \\
\text { Deviation }\end{array}$ & $\begin{array}{c}\text { Std. Error } \\
\text { Mean }\end{array}$ \\
\hline $\begin{array}{l}\text { costsavin } \\
\mathrm{g}\end{array}$ & 250 & 4.118 & 0.6112 & 0.03866 \\
\hline $\begin{array}{l}\text { timesavin } \\
\mathrm{g}\end{array}$ & 250 & 4.1656 & 0.62448 & 0.0395 \\
\hline $\begin{array}{l}\text { extensive } \\
\text { search }\end{array}$ & 250 & 4.2187 & 0.60358 & 0.03817 \\
\hline $\begin{array}{l}\text { unlimted } \\
\text { excess }\end{array}$ & 250 & 4.2 & 0.54423 & 0.03442 \\
\hline
\end{tabular}

To test hypothesis that cost saving is the predictor/motivator for online jobseekers one sample $t$ test was applied and the results are present in table 2. The sig value is .003 which is less than .05 are significant showing that cost saving factor is a motivational factor and it motivates job seekers to apply via internet other than traditional method so the hypothesis that cost saving is the predictor/motivator for online job seekers is accepted.

To test hypothesis that time saving is the predictor/motivator for online job seekers one sample t test was applied and the results are present in table 2 . The sig value is .000 which is less than .05 are significant meaning that there is huge influence of time saving factor for online job seekers. It is a fact and discussed earlier in literature review that online job seekers apply quickly for many organizations job portal and they needs response on spot. So the hypothesis that time saving is the predictor/motivator for online job seekers is accepted.

To test hypothesis that extensive search is the predictor for online job seekers one sample $t$ 
test was applied and the results are present in table 2. The sig value is .000 which is less than .05 are significant meaning that extensive search is the motivational factor for online job seekers so the hypothesis that extensive search is the predictor/motivator for online job seekers is accepted.

To test hypothesis that unlimited excess is the predictor for online job seekers one sample $t$ test was applied and the results are present in table 2 . The sig value is .000 which is less than .05 are significant meaning that unlimited excess to different organizations web portal is a motivational factor for online job seekers so the hypothesis that unlimited excess is the predictor/motivational factor for online job seekers is accepted.

Table 2: One-Sample Test

\begin{tabular}{|l|r|r|r|r|r|r|}
\hline & \multicolumn{7}{|c|}{ Test Value $=4$} \\
\cline { 2 - 7 } & \multicolumn{7}{|c|}{$\begin{array}{c}\text { 95\% Confidence } \\
\text { Interval of the } \\
\text { Difference }\end{array}$} \\
\cline { 2 - 8 } & $\mathrm{t}$ & $\mathrm{df}$ & $\begin{array}{c}\text { Sig. (2- } \\
\text { tailed) }\end{array}$ & $\begin{array}{c}\text { Mean } \\
\text { Difference }\end{array}$ & Lower & Upper \\
\hline costsaving & 3.053 & 249 & 0.003 & 0.118 & 0.0419 & 0.1941 \\
\hline timesaving & 4.193 & 249 & & 0.1656 & 0.0878 & 0.2434 \\
\hline extensivesearch & 5.728 & 249 & & 0.21867 & 0.1435 & 0.2939 \\
\hline unlimtedexcess & 5.811 & 249 & 0 & 0.2 & 0.1322 & 0.2678 \\
\hline
\end{tabular}

\section{Discussion and Conclusion}

The study reveals that that e-recruitment is popular with applicants and that its popularity is increasing as the internet continues to become an accepted and convenient medium for a whole range of transactions. The above results show as previously discussed literature review did entail these motivators to be key in rise of e-recruitment in lieu of traditional methods.

The study findings conclude all the motivators of online job seeking to have positive and significant relationship with E-recruitment. Since the results also state cost saving as good motivator for online job seekers which says this form of recruitment is for sure the new dominant force to come in foreseeable future.

E-recruitment in its rise has created a major revolution in terms individuals being aware of more opportunities through minimal cost, less time, extensive search in terms of finding most appropriate and diverse kinds of jobs and unlimited accessibility has broken all the landscape barriers that once exist and opportunities were lying in wait for few prospective candidates. The above results elucidate that cost saving, time saving, extensive search and unlimited excess to are predictors/motivators for prospective job seekers to use e-recruitment in lieu of traditional methods used by applicants. All the motivators seemed to have positive relationship in the adoption of E-recruitment for in terms of online Job Seeking. The study 
illustrates what are necessary areas individuals in form of job seekers look out for when using e-recruitment. Many organizations must be diligent in terms of how to better make their websites in order to better cater their needs. Also university needs to build their websites in order to maximize job seeker participation in order to cater more people in the dynamics of e- recruitment.

\section{References}

Barber A. E., Recruiting employees (CA: Sage Publications, 1998).

Barber L., E-recruitment Developments (Brighton: The Institute for Employment Studies, 2006).

Cappelli P. (2001), "Making the most of on-line recruiting”, Harvard Business Review 79(3): 139-146.

Chapman D. S. and Webster J. (2003), "The use of technologies in the recruiting, screening, and selection processes for job candidates", International Journal of Selection and Assessment 11(2-3): 113-120.

Edgley K. (1995), "The best job in the world may be one click away", the Times, 11 October.

Galanaki E. (2002), “The decision to recruit online: a descriptive study”, Emerald Career Development International 7(4): 243-251.

Garc1'a-Izquierdo A. L., Aguinis H. and Ramos-Villagrasa P. J. (2010), "Science-

Practice Gap in e-Recruitment", International Journal of Selection and Assessment 18(4): 432-438.

Lang S., Laumer S., Maier C., Eckhardt A. (2011), "Drivers, challenges and

Consequences of E-recruiting: Proceeding: SIGMIS-CPR'11

Onrec (2005), Statistics $\tilde{n}$ the growth of online recruitment, The Online Recruitment

Parry E. and Tyson S (2008), "An analysis of the use and success of online recruitment methods in the UK", Human Resource Management Journal 18(3): 257-274.

Pearce C. G. and Tuten R. L. (2001), "Internet recruiting in the banking industry", Business Communication Quarterly 64(1): 9-18.

Pin J. R., Laorden M.,and Sáenz-Diez I. (2001), "Internet Recruiting Power: Opportunities and Effectiveness", International Research Centre on Organizations (IRCO), Research Paper no. 439, July.

Smith A. D. and Rupp W. T. (2004), "Managerial challenges of e-recruiting: extending the life cycle of new economy employees", Emerald online information review 28(1): 61-74.

Stone D. L. , Stone-Romero E. F. , Lukaszewski K. (2006), "Factors affecting the acceptance and effectiveness of electronic human resource systems”, Human Resource Management Review 16(2): 229-244.

Suvankulov F., Lau M. C. K., Chau F. H. C. (2012), "Job search on the internet and its outcome”, Emerald Internet Research 22(3): 298-317. 
Thompson L. F., Braddy F. W., Wuensch K. L. (2008), "E-recruitment and the benefits of organizational web appeal”, Computers in Human Behavior 24(5): 2384-2398. 